\title{
Wage Divergence and Unemployment: The Impact of Insider Power and Training Costs ${ }^{1}$
}

\author{
July 2000
}

\section{Joan Muysken* and Thomas Zwick**}

*Maastricht University

Department of Economics/ MERIT

P.O. Box 616

6200 MD Maastricht, The Netherlands

e-mail: j.muysken@algec.unimaas.nl
**Centre for European Economic Research (ZEW)

P.O. Box 103443

68034 Mannheim, Germany

e-mail: zwick@zew.de

\section{Abstract}

The US labour market is characterized by a high skill wage mark-up and low unemployment, while the German labour market has a low skill wage mark-up and a high, mainly unskilled unemployment rate. This paper adds an innovative labour supply explanation to the discussion how these distinct labour market equilibria could arise.

Skill-biased technological change induces training needs for the employees willing to work in the skilled labour market and increases relative skill demand. In a simple general equilibrium model, this paper shows that skilled insiders in the USA enjoy higher rents and increase the skilled wage mark-up stronger than in Germany in the wake of skill-biased technological change. The reason is that the unskilled outsiders in the USA do not possess a powerful credible threat to improve their position. This is a consequence from higher training and education costs in the USA for unskilled employees and unemployed. In Germany, the lower skill wage mark-up leads to an increased relative skill demand which is not matched by the skill supply and therefore mis-match unemployment arises.

JEL-codes: J24, J31, O33

Key Words: Mis-match unemployment, training costs, skill biased technological change, Labour supply

\footnotetext{
${ }^{1}$ This paper was conceived during Joan Muysken stayed at ZEW as a guest professor. He wants to thank the ZEW for its hospitality. Usefull comments by Andries de Grip, Clemens Kool, Erik de Regt and participants at the MiMa colloquium in Maastricht are gratefully acknowledged.
} 


\section{Introduction}

Since the early 1980s, skill demand seems to have increased stronger than skill supply (see, for example, Johnson, 1997). In the wake of this trend two different reactions can be distinguished on the labour market. In some countries especially unskilled unemployment increased, mainly resulting from mis-match (see for example Manacorda and Petrongolo, 1999 or Acemoglu and Pischke, 1999), while in other countries the skilled wage mark-up increased (see for example Juhn, Murphy and Pierce, 1993 or Nickell and Bell, 1996). The differences in reactions of the national labour markets and their institutional reasons attracted a lot of attention in the literature (see for example the survey in Chennels and Van Reenen, 1999). In this paper, we focus on the labour market situation in the United States and Germany. The reason is that these countries are in a sense the most extreme and pure cases with respect to the development of relative skilled wages and unemployment. In addition, several studies discuss the differences in the institutional settings on the labour markets in both countries and their consequences, see for example Acemoglu and Pischke (1999), Freeman and Schettkat (1999), Siebert (1997), or Berg (1994).

In the USA, on the one hand, skilled workers have enjoyed higher wage mark-ups in recent years, while unskilled wages fell and skilled wages increased. ${ }^{2}$ On the other hand, the total unemployment ratio cyclically moved around $5 \%$ and declined further in recent years. ${ }^{3}$ In Germany, however, unemployment increased in steps after the adverse shocks in 1982 and 1992 while it barely declined in the boom periods at the end of the nineties. ${ }^{4}$ On the other hand, median earnings of skilled and unskilled workers moved parallel in all sectors. ${ }^{5}$ Therefore in Germany relative skilled wage mark-ups are constant and lower than in the USA, but unemployment is higher and affects mainly the unskilled. ${ }^{6}$

Both stylized facts, that of higher skilled wage mark-ups and that of higher unemployment, are denoted by Krugman, Freeman and others as two sides of the same coin (see, for example, Fitzenberger, 1999). They are often associated with one driving force, the so-called skill biased technological change that increases relative skill demand and affects all

\footnotetext{
2 Topel (1997) shows for example that the wages of workers at the $10^{\text {th }}$ percentile fell by roughly 26 percent between 1969 and 1994 in the USA while the wage of workers in the $90^{\text {th }}$ percentile rose by about 10 percent. Several empirical studies indicate that returns to schooling are more than compensating and increasing. See, for instance, Juhn et al. (1993), Johnson (1997), Topel (1997), OECD (1996a), and Acemoglu and Pischke (1999).

${ }^{3}$ See, for example OECD (1999a) and Manacorda and Petrongolo (1999).

${ }^{4}$ See, for example OECD (1999a).

5 See Figure 1 in Steiner and Mohr (1998).

${ }^{6}$ See also Fitzenberger (1999).
} 
countries in a comparable manner. Explanations of the evolution of the two separate equilibria in the wake of skill biased technological change in the USA versus Germany frequently refer to wage rigidities or effective minimum wage protection in Germany. ${ }^{7}$ This conventional explanation of the two sides of one coin phenomenon has recently been challenged, however. On the one hand, several authors assert that the rigidities are introduced in the models in a merely ad hoc way and that they are not based on empirical facts, see for example Nickell (1997), Fitzenberger (1999, p. 3) or Card and Krueger (1995). On the other hand, it is criticized that the wage rigidity explanation is partial in two ways: It keeps skill supply exogenous and it only focuses on the labour market and does not take other markets into account, see for example Atkinson (2000).

The present paper explains the evolution of the two equilibria in both countries from different institutional settings on the labour markets (see also Atkinson, 2000, and Davis, 1998) and therefore endogenizes their explanation. Further, goods market repercussions of skill biased technological changes are taken into account. Finally, this paper introduces a new argument to the debate: skill biased technological change has a positive impact on skill supply and training. Skill biased technological change increases skill rents and therefore the motivation to invest in training. On the other hand, it boosts innovation dynamics. ${ }^{8}$ As a consequence, the product cycle has shortened and the rate of implementation of innovations in firms has risen in all developed countries. There is a clear relation between innovations and training costs in firms, because changes in processes and products always result in training needs and therefore the necessity of life long employee training is nowadays more important. ${ }^{9}$ Training needs are positively correlated with the qualification level of the employee (see Acemoglu and Pischke, 1999 or Pannenberg, 1995 for German individual data). Therefore, we can also state as a stylised fact that training needs and training costs for skilled jobs increased in the wake of skill biased technological change. Skill biased technological change also may be the origin of mis-match unemployment when firms are constrained by skilled labour supply. At a given skilled wage mark-up skill demand increases stronger than skill

\footnotetext{
${ }^{7}$ See Krugman (1995), Siebert (1997), Davis (1998), and Chennels and Van Reenen (1999).

${ }^{8}$ Direct measures of innovation dynamics like product cycles or changes in work organization caused by innovations are not easy to obtain. Therefore the input for research and development have to be taken as an indication for innovation dynamics, see also Chennels and Van Reenen (1999). The share of civilian research and development expenditures on GNP increased in the eighties in all OECD countries (it only declined slightly in the first years of the 90's in the USA), cf. OECD (1996b)

9 See for example Ebling et al. (1999). Bartel and Sicherman (1998) also show that several proxies for technological change are positively correlated with training.
} 
supply and as a consequence total unskilled labour demand decreases, see for example Manacorda and Petrongolo (1999).

In a simple general equilibrium framework, this paper derives two equilibria after the shift in relative skilled labour demand due to skill biased technological change: One equilibrium with a high skilled wage mark-up and low unemployment and one with a lower skilled wage mark-up and (unskilled) unemployment. The crucial institutional factor which is responsible for the different labour market outcomes in Germany and the USA is according to our model: training costs for unskilled workers are higher in the USA than in Germany. In Germany, the threat of unskilled outsiders to train, enter the skilled labour market and replace the insiders is stronger than in the USA, because their training costs are lower. The skilled insiders in Germany react with a lower relative wage mark-up to the outsider threat. The lower relative skilled wage leads to an increased skilled labour demand which is not satisfied, because not sufficient unskilled outsiders are motivated to invest in training. Therefore German firms are constrained in their skill demand and mis-match unemployment occurs. In the USA, fewer additional skilled employees are demanded, because the skilled wage markup is higher. Therefore less mis-match unemployment is incurred.

In section 2, a basic general equilibrium framework is developed where all employees have an adequate job. When relative skill demand increases, due to skill biased technological change, relative and absolute skilled and unskilled labour demand changes, depending on the elasticity of relative skill supply. In the next section, insider wage setting behaviour is introduced and the two labour market equilibria are derived. In the last section, we interpret these results in the light of the empirical observations in the USA and Germany and end with some policy conclusions. 


\section{A general equilibrium model with skill biased technological change}

We set out with the description of a standard two-goods, two-factor general equilibrium model (compare also Davis, 1998). Then we show how the impact of skill biased technological change on the labour market depends on the reaction of labour supply.

\subsection{The general structure}

We distinguish between skilled labour $H$ and unskilled labour $L$ as factors of production, with wages $w_{H}$ and $w_{L}$, respectively. The relative wage is $w=w_{H} / w_{L}$. Total supply of skilled and unskilled labour is $n$ and $m$, respectively, and relative supply is given by $h^{*}=n / m$. Moreover, two goods are produced under constant returns to scale: a skill-intensive good $X$ and a skillextensive good $Y$, where $P$ is the relative price of $X$ to $Y$, i.e. $P=P_{X} / P_{Y}$. Since we assume $w_{H}$ $>w_{L}$ and $n<m$, throughout the analysis, we impose $w>1$ and $h^{*}<1$.

Let consumers have the following utility function:

$$
U=\left[X^{\rho}+Y^{\rho}\right]^{1 / \rho},
$$

with $0<\rho<1$ and $1 /(1+\rho)$ being the elasticity of substitution between $X$ and $Y$. Maximization of utility subject to the budget constraint $I=P_{X} X+P_{Y} Y$, with $I$ denoting income, yields:

$$
\frac{X}{Y}=P^{\frac{1}{\rho-1}},
$$

which shows that the relative consumption of skill-intensive to skill-extensive goods is inversely related to the relative price, since $1 /(\rho-1)<0$.

The production of goods is represented by a Cobb-Douglas production function:

$$
\begin{aligned}
& X=A\left(H_{X}\right)^{\alpha}\left(L_{X}\right)^{1-\alpha} \\
& Y=\left(H_{Y}\right)^{\beta}\left(L_{Y}\right)^{1-\beta} \quad \text { with } \quad 0<\beta<\alpha<1,
\end{aligned}
$$


with $H_{i}, L_{i}$ denoting the use of production factors $H$ and $L$ in the production of good $i$. Furthermore $\beta<\alpha$ indicates that $X$ is the skill-intensive and $Y$ the skill-extensive good. The factor $A$ is a productivity index of the skill intensive goods producing sector.

Profit maximization subject to equations (3) and (4) yields:

$$
w=k_{l} A^{1 /(\alpha-\beta)} P^{1 /(\alpha-\beta)},
$$

where $k_{1}>0$ is a constant. ${ }^{10}$ This implies that at equilibrium on the goods markets, the skilled wage is higher, the higher the price of skill-intensive goods and the higher the efficiency of production in this sector. ${ }^{11}$ The implied positive relation between $w$ and $P$ at the equilibrium on the goods markets is presented in the second quadrant of Figure 1 below.

Aggregate demand for labour is given by:

$$
\begin{aligned}
& H=H_{X}+H_{Y,} \\
& L=L_{X}+L_{Y} .
\end{aligned}
$$

Arbitrage between sectors, given the consumption behaviour implied by equation (2), then results in a negative relation between relative wages $w$ and relative demand for labour $h \equiv$ $H / L$, which is increasing in $A .{ }^{12}$ The demand curve for skilled relative to unskilled labour is downward sloping for two reasons. First, a higher relative wage implies that skilled workers become more expensive, hence they are demanded less in the production of both goods. Second, apart from this direct effect, there is also an indirect effect. A higher relative wage means that the skill-intensive good becomes more expensive (see the equilibrium on the goods markets curve) and therefore consumer demand shifts towards the skill-extensive good.

Hence demand for skilled workers declines for that reason, too. The resulting downward sloping demand curve $h^{d}$ is presented in the first quadrant of Figure 1.

The simultaneous equilibrium on both the labour and goods market is represented in Figure 1, for a given relative factor endowment $h^{*}$. Labour markets equilibrium at full employment $h^{*}$ fixes relative wages $w$ at $w^{*}$ - see point $\mathrm{E}$ on the demand curve for labour in the first quadrant. The equilibrium wage $w^{*}$ should also be consistent with the goods markets equilibrium at $P^{*}$ - see the curve in the second quadrant.

\footnotetext{
${ }^{10}$ This is elaborated in the annex.

${ }^{11}$ An interpretation of this relation is that when the relative price $P$ increases, it is easier to make profits on $X$. Therefore, skills are lured away from $Y$ to $X$ and $w=w_{H} / w_{L}$ increases.
} 


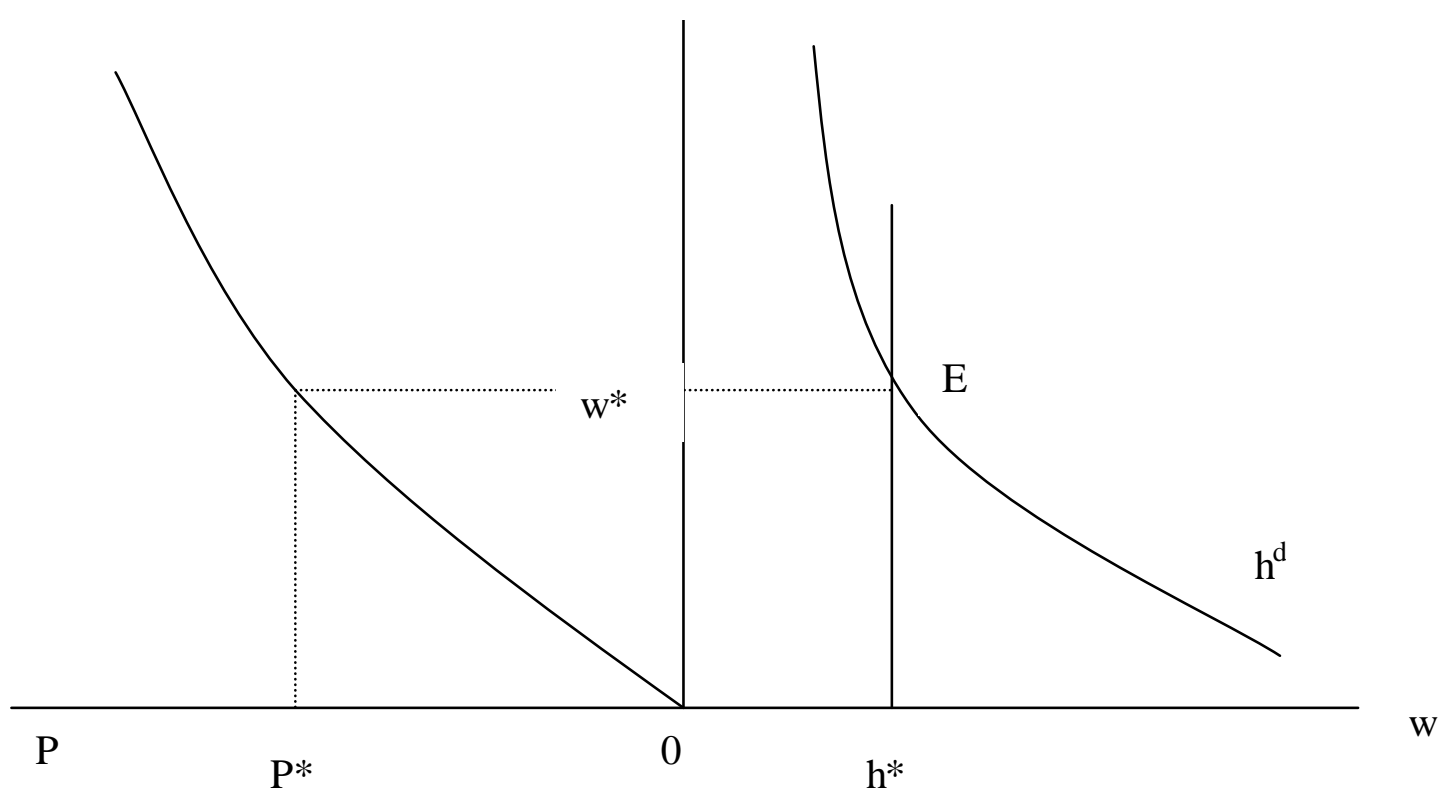

Figure $1 \quad$ Equilibrium on both the goods markets and the labour markets

\subsection{The impact of skill biased technological change}

Technological change manifests itself in this model as an increase in $A$ in equation (3), which means that more skill-intensive goods can be produced with the same labour input. ${ }^{13}$ As a consequence, relative demand for skilled labour increases at the same relative wage rate, since it becomes more profitable to employ labour in skill intensive goods. Therefore, skill biased technological change shifts the demand curve for labour outwards, as indicated by $h(w)$ $=h^{d 2}$ in Figure 2 below.

It is obvious that the new labour market equilibrium depends on the reaction of labour supply. We discuss three possible outcomes here: wage flexibility and either inelastic labour supply or perfectly elastic labour supply and wage rigidity with inelastic labour supply. In the first two cases full employment prevails, while in the third scenario, unemployment is incurred.

In the case of wage flexibility and ine lastic labour supply, the supply of skilled and unskilled workers does not change. Therefore relative supply remains in $h^{*}$ and the new equilibrium is found at point $\mathrm{C}$ in Figure 2, at the wage $w^{n}$. The relative wage increases because relative demand for skilled workers has increased, whereas relative supply hasn't i.e. $h\left(w^{n}\right)=h^{*}$. Notice that in point $\mathrm{C}$ both unskilled and skilled labour demand do not change

\footnotetext{
12 This is elaborated in equation (11) in the annex.

${ }^{13}$ The same effect would be reached when productivity of skilled labour increases relative to that of unskilled labour, in the production of both goods.
} 
after skill biased technological change, because skilled wages increased and unskilled wages decreased. $^{14}$

Figure 2 The impact of skill biased technological change and labour supply

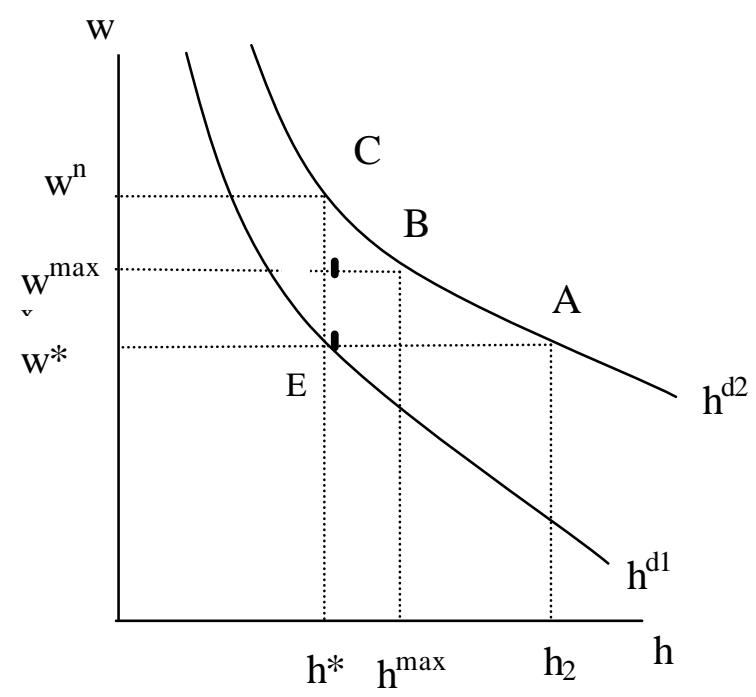

The other extreme is perfectly elastic labour supply, which implies that sufficient unskilled workers skill themselves in order to adapt to the higher relative and total demand for skilled workers. The new equilibrium is characterized by point $\mathrm{A}^{15}$ in Figure 2, with relative demand at $h_{2}=h\left(w^{*}\right)$. One can easily derive that the number of skilled workers in the new equilibrium situation now equals: ${ }^{16}$

$$
H=n+m \frac{h\left(w^{*}\right)-h^{*}}{1+h\left(w^{*}\right)}
$$

The situations in points $\mathrm{A}$ and $\mathrm{C}$ in Figure 2 correspond to a perfectly elastic and inelastic supply of labour, respectively. It is obvious, that depending on the elasticity of labour supply, the new equilibrium is found somewhere on the relative demand curve $h(w)=h^{d 2}$ between points $\mathrm{A}$ and $\mathrm{C}$.

\footnotetext{
${ }^{14}$ Whether the production of skilled goods has increased relative to unskilled goods or not, and hence whether the relative price has decreased or not, depends on the parameters of the model, see equation (11) in the annex .

${ }^{15}$ Since the relative wage has remained the same, but relative supply of skilled workers has increased, much more skill intensive goods are produced and sold at a lower relative price.

${ }^{16}$ This can be derived by solving $\Delta$ from $h_{2}=(n+\Delta) /(m-\Delta)$, while $h^{*}=n / m$.
} 
In all these cases wage flexibility has to be assumed. The assumption of wage flexibility is questioned widely in the literature, however. Typical reasons for that are fixed minimum wages, wage bargaining or insider behaviour. ${ }^{17}$ One may wonder therefore what happens when relative wages are rigid - i.e. they do not fully adjust when technological change occurs. The implications are most clear when labour supply is inelastic.

As we already mentioned above, when labour supply is inelastic the supply of skilled workers relative to the unskilled ones remains at $h^{*}$. If due to complete wage rigidity the relative skilled wage remains at $w^{*}$, relative demand increases to $h_{2}=h\left(w^{*}\right)$, as we know from Figure 2. However, since the supply of skilled workers remains fixed at $n$, demand for unskilled workers is $n / h\left(w^{*}\right)$. Since the supply of unskilled workers is $m$, mis-match unemployment prevails and the number of unemployed unskilled workers, $Z_{L}$, is given by: ${ }^{18}$

$$
Z_{L}=m-n / h\left(w^{*}\right)
$$

This situation is characterized by point $\mathrm{E}$ in Figure 2 . At the wage $w^{*}$ relative demand for skilled workers has increased. This implies that if the absolute supply of skilled workers does not change, absolute demand for unskilled workers decreases.

The above analysis has covered the three extreme cases of relative labour supply and wage rigidity. Depending on the elasticity of supply and the degree of relative wage rigidity, skill biased technological change leads to an outcome which is either on the relative demand curve for labour $h^{d 2}$, between the points $\mathrm{A}$ and $\mathrm{C}$ - in case of flexible wages - or in the area below that curve, bounded by $\mathrm{AE}$ and $\mathrm{CE}$ - in case of wage rigidities. We elaborate this below for the case of insiders and outsiders.

\footnotetext{
${ }^{17}$ See, for instance, Davis (1998), Blanchard and Summers (1986), Lindbeck and Snower (1988), Siebert (1997), and Nickell (1997).

${ }^{18} Z_{L}$ is positive because $h_{2}>h^{*}$.
} 


\section{Insider power and skill-biased technological change}

The starting point of the analysis is the initial equilibrium situation as it is depicted in Figure 1 in point $E$ with a relative wage $w^{*}$ and relative demand $h^{*}$. The $n$ skilled workers are now considered as insiders, working on well paid jobs, whereas the $m$ unskilled workers are the outsiders. In equilibrium there is full employment for both skilled and unskilled workers.

Let there be an exogenous shock, for instance caused by innovative activities of high tech firms that improve the productivity in the skill-intensive goods sector. Therefore the relative demand curve for labour shifts from $h^{d 1}$ to $h(w)=h^{d 2}$, as has been discussed in Figure 2 above. Now the question is what happens to relative wages and prices, skill supply, and the labour market equilibrium if the skilled insiders are able and willing to set skilled wages and constrain the entry of unskilled outsiders to the skilled labour market.

We assume that innovations always induce training costs that have to be born by the employees. ${ }^{19}$ In addition, skilled jobs require higher training efforts than unskilled jobs, see for example Acemoglu and Pischke (1999). Therefore both insiders and outsiders have to train themselves and incur training costs in order to work on the skilled labour market after the introduction of the new technology. Notice that (a part of the) training costs are sunk. The decision to train has to be taken before skill demand is known (Muysken and Zwick, 1999) and therefore the training costs that do not lead to a wage mark-up are lost. This is the case, for example, if no adequate job is found and therefore the higher labour productivity can not be used. The more specified the knowledge or the quicker it is outdated, the higher is the risk that the training costs can not be re-earned after the investment. In this model it is assumed for simplicity that the knowledge necessary to handle the innovation is outdated after one period (when the new innovation arrives). If the workers therefore do not get a job in the investment period, the investment costs are completely lost.

Work in the unskilled labour market does not require training costs in our model. As a consequence, skill supply is endogenous and subject to a rational expected cost/benefit calculation for training. Usually the acquisition of skills is not restricted and we can conclude therefore that more unskilled employees invest in training when the pay-off of being skilled increases with respect to training costs. Benefits of training are the wage mark-up for skilled workers when they find an adequate job and a reduction in the unemployment hazard, because the qualification level is negatively related with unemployment rates (Layard, Nickell and 
Jackman, 1991: 286-292, OECD, 1998a, or Acemoglu and Pischke, 1999). This is partly due to bumping-down effects, in other words skilled workers replace unskilled workers while those unskilled workers do not find work any more (Van Zon, Muysken, and Meijers, 1998).

We show now that the sunk cost property of training gives insiders the possibility to prevent outsiders from entering the skilled work force.

\section{The behaviour of insiders}

The $n$ insiders determine first whether they invest in training and stay in the skilled labour market. If they do, they also determine their wage demand, which leads to the skilled wage mark-up. Outsiders then can react to the wage mark-up set by the insiders.

When the insiders want to work in the skilled labour market, they have to pay training $\operatorname{costs} c_{n}$ that are necessary to work efficiently after the implementation of skill biased technological progress. Note that for analytical simplicity, training costs $c_{n}$ are defined relative to the unskilled wage, $w_{L}$. When the insiders work in the unskilled labour market, training is not necessary. Moreover, when working in the unskilled sector the skilled insiders do not have to fear unemployment because they are able to bump down outsiders. Thus only unskilled outsiders face the problem of unemployment when total labour demand is lower than total labour supply.

From the above it follows that insiders decide to invest in training when:

$$
c_{n} \leq w-1
$$

With the relative wage at $w^{*}$ we assume that the insiders do cover their training costs. Hence point $E$ in Figure 2 is feasible.

It is tempting, however, for the insiders to aim at a higher wage, but it is never in the interest of the insiders to set a skilled wage that leads to a skilled labour demand lower than $n .^{20}$ Therefore, the highest relative wage the insiders set is $w^{n}$ where skilled labour demand is equal to the number of insiders $n$, i.e. $h\left(w^{n}\right)=h^{*}$ - compare point $C$ in Figure 2.

On the other hand, for the insiders it is never utility-maximizing to set a wage that allows outsiders to substitute them, see, for example, Lindbeck and Snower (1990), or Fiorillo, Santacroce, and Staffolani (1999). This means that the relative wage only is set at the

\footnotetext{
${ }^{19}$ Even when the firm pays for the training, the workers have to invest their working time and effort and therefore always bear part of the costs.

${ }^{20}$ This is usually found in insider-outsider models, see for example Blanchard and Summers (1986), Lindbeck and Snower (1988), Lindbeck and Snower (1994) ), or Fiorillo, Santacroce, and Staffolani (1999).
} 
level $w^{n}$ when the outsiders have no credible threat to replace them, otherwise the insiders set a lower wage. In order to analyse this further, we first have to look at outsider behaviour.

\section{The behaviour of heterogeneous outsiders}

The main difference between outsiders and insiders is that the outsiders did not invest in education and training in the previous period and therefore they worked in the unskilled labour market, see also Lindbeck and Snower (1990, 1994). As they do not have enough education and previous training and did not get the insiders' training-on-the-job, it is more costly for the outsiders to acquire the necessary training in order to compete with the insiders. Therefore $c_{m}>c_{n}$ where $c_{m}$ are the outsiders' training costs, also relative to the unskilled wage.

Outsiders have three options: either they do not invest in training and education and stay outside the skilled labour market, or they imitate the insiders and get the skilled jobs demanded by the firm that are not occupied by the insiders. Finally, they may substitute the insiders by offering a higher profit to the firm than the insiders. We assume that in the initial situation before the technology shock, i.e. at point E in Figure 2, the outsiders do not pose a credible threat to replace the insiders.

Usually, it is assumed in the insider-outsider literature that outsiders are homogeneous in their capabilities (see for example Blanchard and Summers, 1986, Lindbeck and Snower, 1988). This implies, however, that all outsiders have to invest in human capital in order to pose a credible threat to replace the insiders or to join them. If we introduce heterogeneous outsiders, this does not hold any more and it is possible that for example the insiders set the wage such that they avoid to be substituted by all outsiders, but nevertheless some outsiders still have an interest to join the insiders. Therefore, we obtain a much richer picture of the possible outcomes with heterogeneous outsiders. ${ }^{21}$

In each society there are different degrees of skills which roughly correspond to different levels of schooling - therefore it is useful to distinguish a limited amount of groups of outsiders. In our analysis we distinguish between three groups for analytical simplicity, the extension to more groups then is rather straightforward. These three groups differ in their ability to obtain the required level of skills.

\footnotetext{
${ }^{21}$ Compare also the recent insider-outsider models in Lindbeck and Snower (1994), or Fiorillo, Santacroce and Staffolani (1999) where all workers are heterogeneous and insiders have market power because they are more productive than the outsiders.
} 
For obvious reasons we now slightly change our notation and assume that there are (1 $+b) m$ outsiders. A fraction $b /(1+b)$ of the $(1+b) m$ outsiders has a very low probability to obtain the required skill level after schooling: we therefore call them the "backward" outsiders. The "backward" outsiders never have an incentive to invest in human capital and therefore never want to join or replace the insiders. Of the remaining $m$ outsiders that might train, a fraction $g<1$ succeeds with certainty in obtaining the required skill level when they train themselves, they are the "clever" outsiders. The other part, a fraction $1-g$, which consists of "normal" outsiders has a probability $p<1$ to obtain the required skill level after having participated in the training programme. Thus we distinguish between $\mathrm{gm}$ "clever" outsiders, (1-g)m "normal" outsiders and $\mathrm{bm}$ "backward" outsiders. Members of each group of outsiders pursue their own interests, taking into account the actions of the other outsiders. ${ }^{22}$ This implies, for instance, that when investing in training is in the interest of the normal outsiders only when the clever outsiders also invest in training, the normal outsiders only train when it is in the interest to invest in training for the clever outsiders, too.

In the following, we show that there are three main equilibria depending on outsider investment costs, the share of clever and normal outsiders and the insider wage demand. In the first equilibrium, the outsiders do not pose a credible threat and the insiders therefore can set the wage as it pleases them (i.e. at $w^{n}$, see Figure 2). In the second and third equilibrium, the $m$ clever and normal outsiders have a credible threat and therefore the insiders reduce their wage demand such that they just cannot be substituted. In the second equilibrium, it is not in the interest of the outsiders to join the insiders, whereas in the third equilibrium, it is in the interest of the clever outsiders to join the insiders.

\section{The outsiders' threat condition}

We assume that the number of clever outsiders is relatively low, when compared to the number of insiders, while the number of clever and normal outsiders taken together exceeds the number of insiders. Thus we assume: $g m<n<m$. In the "threat" case, clever and normal outsiders try to outperform the insiders. This is only possible when the clever and normal outsiders co-operate, since the number of clever outsiders alone is too small to pose a credible threat to replace the insiders.

\footnotetext{
${ }^{22}$ This assumption is also made in Lindbeck and Snower (1994).
} 
There are more outsiders than insiders. Therefore, if the outsiders replace the insiders, not all $m$ outsiders, but only the fraction $h^{*}$ find a skilled job and earn the skilled wage, while others remain on the unskilled labour market and are therefore over-educated. Since they invested in training, however, the former outsiders do not run the risk to become unemployed. It is clear that the previous insiders want to avoid this situation, because they would as a conwequence work on the unskilled labour market, too, and even may become unemployed.

When we first look at the normal outsiders, their expected utility $U^{t h r}{ }_{1-g}$ - relative to the unskilled wage - associated with outperforming is: ${ }^{23}$

$$
U_{1-g}^{t h r}=\frac{h^{*}}{g+p(1-g)} p w+\left[1-\frac{h^{*}}{g+p(1-g)} p\right]-c_{m}
$$

The normal outsiders are only motivated to train and outperform the insiders, if their expected utility is lower compared to the utility obtained when they do not invest in human capital. In the latter case, a fraction $h * / h(w)$ is employed in unskilled jobs, whereas the remaining unskilled outsiders earn $s$ - where $s \leq 1$ is the outside option (unemployment benefit) relative to the unskilled wage. The associated utility $U^{\text {notr }}$, also relative to the unskilled wage, then is:

$$
U^{n o t r}=h^{*} /[h(w)(1+b)]+\left[1-h^{*} /[h(w)(1+b)] s .\right.
$$

As one might expect, this utility increases towards 1 , thus in absolute terms to the unskilled wage, when the relative wage increases to $w^{n}$, because all outsiders find a job at $w^{n}$ (see point $\mathrm{C}$ in Figure 2). ${ }^{24}$

For the clever outsiders the utility when investing in human capital together with the normal outsiders in order to outperform the insiders, $U_{g}^{t h r}$, is analogously given by:

$$
U_{g}^{t h r}=\frac{h^{*}}{g+p(1-g)} w+\left[1-\frac{h^{*}}{g+p(1-g)}\right]-c_{m} .
$$

This utility clearly exceeds $U_{1-g}^{t h r}$ from equation (10) at a given wage rate. Thus when it is profitable for normal outsiders to threat the insiders, it certainly is for the clever outsiders. ${ }^{25}$

\footnotetext{
${ }^{23}$ We assume that anybody who has followed training, is preferred to get a low skilled job and therefore does not run the risk of unemployment.

${ }^{24}$ Now we have $h\left(w^{n}\right)=h * /(1+b)$.
} 
The utility not to invest in training for the clever outsiders is the same as for the normal outsiders in equation (11).

Comparison of the utility levels in equations (10) and (11) shows that it is in the interest of the normal and clever outsiders to invest in training if $U_{1-g}^{t h r}>U^{\text {notr }}$. For a given relative wage $w$ should therefore hold:

$$
c_{m}<\frac{h^{*}}{1+g(1-p) / p}(w-1)+\left[1-\frac{h^{*}}{(1+b) h(w)}\right](1-s)
$$

When equation (13) holds, the $m$ outsiders pose a credible threat to replace the insiders. We call this the "threat" condition.

It is interesting to note that the right-hand side of the threat condition (13) is an increasing function of the relative wage $w$ as long as the demand elasticity of skilled relative to unskilled labour to the relative wage, $\eta(h, w)$, is not too large. ${ }^{26} \mathrm{We}$ assume that this condition is satisfied. ${ }^{27}$ Hence the outsider threat is more credible when the relative wage increases, i.e. in that case the outsiders also invest in training when the investment costs are high. The intuition is that with higher relative wages the wage premium increases and can be shared by a much larger number of outsiders who become insider.

The threat condition is depicted as the line TT in Figure 3. As we argued above, it is increasing in the relative wage and lies below training costs $c^{m}$ for outsiders at the wage $w^{*}{ }^{28}$ When the training costs exceed the curve at a certain wage, condition (13) is not met and hence the outsiders cannot pose a credible threat. In the area below the curve threats are credible and the insiders are forced to reduce their wage demand below $w^{n}$.

Figure 3 shows that the threat of clever and normal outsiders is only credible as long as the training costs for outsiders are not too high:

$$
c_{m}<\left(w_{n}-1\right) h * /[1+g(1-p) / p]+[b /(1-b)](1-s) .
$$

\footnotetext{
25 It is also clear that $U_{g}^{t h r}<U^{t h r}$, compare equations (10) and (12), hence the clever outsiders would prefer to threat the insiders by training themselves only. This is not credible, however, because $g m<n$.

${ }^{26}$ This means that $-\eta(h, w)<\frac{(1+b) p}{p+(1-p) g} \frac{w}{1-s} h(w)^{2}$ should hold.

${ }^{27}$ Typical values for the demand elasticity of skilled relative to unskilled labour are in the range -2 to -4 , taking cross effects into account, see Table 5.8 in Fitzenberger (1999).

${ }^{28}$ This implies that holds: $c_{m}>(1-s)\left[1-h * /\left\{(1+b) h\left(w^{*}\right)\right\}\right]+\left(w^{*}-1\right) h * /[g+p(1-g)]$. The costs of training for insiders have to be $c_{n}<w^{*}-1$ at the same time. This is perfectly possible, even when $c_{n}=c_{m}$.
} 
From equation (14) one sees that, the higher the share of backward outsiders, $b /(1-b)$, the lower the number of normal and clever outsiders, $m$, and the higher the probability $p$ that the normal outsiders succeed in training, the more credible is the threat they pose to the outsiders. Therefore it is highly improbable that the backward outsiders are motivated to invest in human capital at $w^{n}$ : they have a much lower probability of success when educating themselves and if they invest, this would increase the number of outsiders and therefore the risk of the outsiders to be over-educated.

Figure 3: The threat and join condition

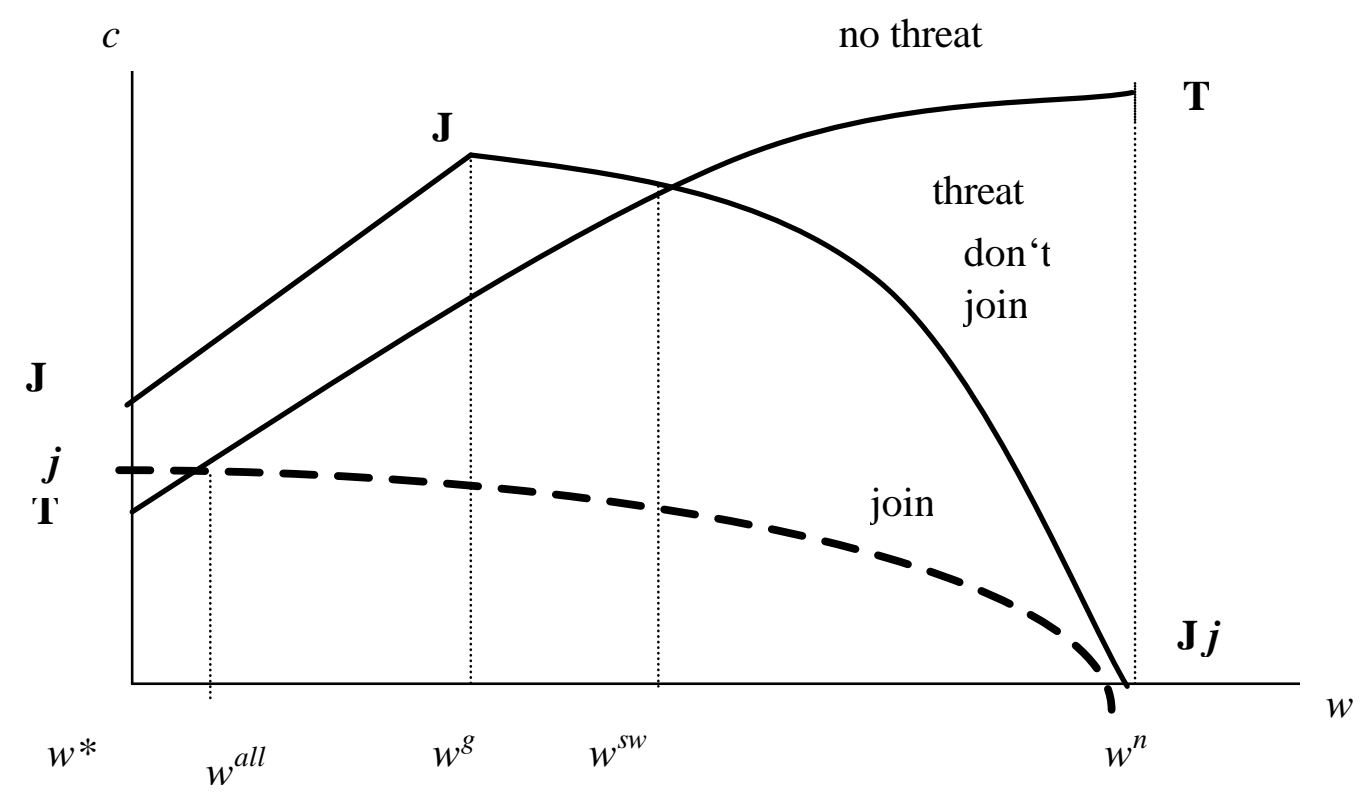

The outsiders' join condition

Another option for the outsiders is to join the insiders. It follows from equation (7) that if the $g m$ clever outsiders invest in training, $m\left[(1+b) h(w)-h^{*}\right] /[1+h(w)]$ outsiders can be employed in the skilled labour market. If this expression exceeds $g m$ at the prevailing wage, all clever outsiders find employment. This is the case when:

$$
\frac{(1+b) h(w)-h^{*}}{1+h(w)}>g
$$

We assume the demand shock to be sufficiently large, the proportion of backward outsiders $b$ to be large enough, or the proportion of clever outsiders $g$ to be small enough, such that this 
condition does hold at the initial wage $w^{*}$ (where the additional demand for skilled outsiders is the highest). Intuitively it should be clear that when the number of joining outsiders exceeds the number of insiders, a very large demand shock is needed to be able to absorb all joining outsiders. Therefore the option to join the insiders without over-education risk only is a relevant option for the clever outsiders and not for the normal outsiders. ${ }^{29}$

The condition (15) implicitly defines $w^{g}$, the relative wage below which all clever outsiders can join, without the risk of having to accept an unskilled job. Notice that those outsiders who stay unskilled run the risk to get unemployed when the relative wage is below $w^{g}$, because skilled labour demand is lower than skilled labour supply. This reduces total labour demand and therefore mis-match unemployment arises. When the wage is below $w^{g}$, the utility $U_{g}^{j}$ of clever insiders, relative to the unskilled wage, to join therefore is given by:

$$
U_{g}^{j}=w-c_{m} \quad w \leq w^{g} .
$$

However, when the wage exceeds $w^{g}$, clever outsiders run the risk to be over-educated and employed in unskilled jobs. In that case the utility $U_{g}^{j}$, relative to the unskilled wage, to join is:

$$
U_{g}^{j}=\frac{1}{g} \frac{(1+b) h(w)-h^{*}}{1+(1+b) h(w)} w+\left[1-\frac{1}{g} \frac{(1+b) h(w)-h^{*}}{1+(1+b) h(w)}\right]-c_{m} \quad w>w^{g} .
$$

Notice that when $w>w^{g}$, all outsiders are employed, because the additional skilled labour demand is satisfied and therefore no mis-match unemployment arises. The same reasoning that led to equation (13) then shows that clever outsiders train themselves and join the insiders, as long as:

$$
\begin{array}{ll}
c_{m}<(w-1)+\left(1-\frac{h^{*}}{(1+b) h(w)}\right)(1-s) & w<w^{g}, \\
c_{m}<\frac{1}{g} \frac{(1+b) h(w)-h^{*}}{1+(1+b) h(w)}(w-1)+\left(1-\frac{h^{*}}{(1+b) h(w)}\right)(1-s) \quad w>w^{g} .
\end{array}
$$

We call this the "join" condition.

\footnotetext{
${ }^{29}$ We assume for simplicity that $\left(h^{*}+g\right) /(b+1-g)<h<\left(h^{*}+1\right) / b$.
} 
One sees that the clever outsiders do not invest in human capital and imitate the insiders if the skill wage mark-up $(w-1)$ is too low or the replacement rate of the unemployed in comparison to the unskilled wage $(l-s)$ is too low. In addition, a low chance to find a suitable skilled job relative to the probability to be over-qualified reduces the motivation of the clever outsiders to join the insiders.

The join condition initially increases almost proportional to the relative wage rate, as can be seen from the right-hand side of equation (17A). However, when we consider the righthand side of the join condition (17B) as a function of the relative wage $w$, it seems plausible that the function is initially increasing and then decreasing in $w:$ at $w^{n}$ it is always equal to zero. ${ }^{30}$ As a consequence the willingness of the clever outsiders to join the insiders decreases at some moment, with an increasing relative wage. The intuition is that although the relative wage is higher, the wage premium is earned by less outsiders and more outsiders are overeducated, because the additional relative demand for skilled workers decreases. Moreover, the threat of unemployment increases, too, which also has a negative impact on the willingness to join the insiders. We assume that the right-hand side of equation (17B) is already decreasing at $w^{g}$, although this is not important for our analysis. ${ }^{31}$ The join condition for the clever outsiders is depicted as the line $\mathrm{JJ}$ in Figure 3. It first increases in the relative wage, until $w^{g}$, and then decreases to zero at the wage $w^{n}$.

Of course it could also be possible that the normal outsiders want to join the insiders, too. As it is implausible that due to skill biased technological change skill labour demand more than doubles (see also footnote 28), normal outsiders always have to enter with the risk of over-education and therefore equation (17A) is not relevant. Normal outsiders therefore enter if:

$$
c_{m}<p \frac{(1+b) h(w)-h^{*}}{1+h(w)}(w-1)+\left(1-\frac{h^{*}}{(1+b) h(w)}\right)(1-s)
$$

It is obvious that the graph of this condition lies below the join condition depicted in Figure 3, because $p<1 / g$. We have depicted this condition as the dotted line $\mathrm{jj}$ in Figure 3 , starting above the TT-line and decreasing to zero at $w^{n}$. It can also start below the TT-line as

\footnotetext{
${ }^{30}$ The right-hand side can be written as: $\frac{1+b}{g} \frac{l(w)-h^{*}}{1+b+l(w)}(w-1)+\frac{l(w)-h^{*}}{l(w)}(1-s)$, with $l(w)=$ $(1+b) h(w)$. The terms before $(w-1)$ and $(1-s)$ are decreasing in $w$. The rate of decrease is increasing with $w$. At low values for $w$, the positive impact of $w$ itself may dominate. However, at $w^{n}$ the right-hand side is always equal to zero.

${ }^{31}$ If it still increases till some value $w^{G}>w^{g}$, we should use $w^{G}$ instead of $w^{g}$ below.
} 
is obvious from comparison of (17B) with $g=l$ with the threat condition (10), but the case presented here has some interesting implications, as we elaborate below.

It is highly interesting to compare the join conditions with the threat condition. The right-hand side of the join condition (17A) of the clever outsiders initially starts at a higher level and increases faster in the relative wage rate, when compared to the threat condition. Therefore the join condition dominates the threat condition till some relative wage rate above $w^{g}$. We denote this wage rate where both conditions become equally binding by $w^{s w}$. When the wage increases above $w^{s w}$, it is profitable for the clever outsiders to switch from joining the insiders to threatening the insiders, together with the normal outsiders - it is obvious that we find $\mathrm{w}^{*}<$ $w^{g}<w^{s w}<w^{n} .32$

When we compare the join condition of the normal outsiders with the threat condition, it might also be profitable for relatively low training costs for the normal outsiders to join. We represent the join condition of the normal outsiders by the jj-line in Figure 3. In that figure we have assumed that the jj-line starts above the TT-line, which only holds for certain specific parameter values. In that case when the wage lies below $w^{\text {all }}$, it is also profitable for the normal insiders to join the insiders instead of to threat them. If the jj-line lies below the TTline for all relative wages, joining is never a feasible option for the normal outsiders. ${ }^{33}$

\section{The interaction of insider and outsider behaviour}

From the analysis above it follows that the $m$ outsiders are able to pose a credible threat when there is a group of normal and clever outsiders, together with a group of backward outsiders, that satisfies equation (14). If that is not the case, the insiders will set the wage at $w^{n}$ and full employment will occur - compare case I in Table 1 below.

Since the insiders want to maximise their utility, they set their wage demand as high as possible. When they are confronted with a credible threat, they therefore always set their wage such that this threat is just deterred, that is, according to the TT-line in Figure 3. Hence, the lower the training costs $c^{m}$ of the outsiders, the lower the wage set by the insiders.

\footnotetext{
${ }^{32} w^{s w}$ can be found from $h\left(w^{s w}\right)=2 h * /\left(1-h^{*}\right)$.

${ }^{33}$ For any value of the relative wage $w$ the following should hold: $h(w)>h *(1+p+g(1-p)) /[(1+b)(p+g(1-p))-$ $h^{*}$ ], compare equations (13) and (18). The value of $w^{\text {all }}$ is defined when this expression is an equality.
} 
From the analysis above, it follows that when the wage thus set exceeds $w^{s w}$, joining is not a feasible option for the outsiders and mis-match unemployment occurs, since relative skill demand is higher than $h^{*}$ and therefore the firms are constrained in their demand for skilled labour. This is equilibrium II in Table 1. When joining is a feasible option, however, at least the clever outsiders join. Since additional skilled demand is lower than the number of joining clever outsiders, investment in training of the clever outsiders goes hand in hand with full employment. The reason is that not all clever outsiders are able to find an adequate job for their skill - cf. equilibrium III. However, when the relative wage is below $w^{g}$, all clever outsiders are able to find adequate jobs after training and relative demand will fall again below $h^{*}$. Hence unemployment will occur - cf. equilibrium IV in Table 1. Finally, it may become profitable for the normal outsiders to invest in training too. This is the case when the relative wage along the TT line will be set below $w^{\text {all }}$. Then, analogous to equilibrium III, training goes hand in hand with full employment, because not all normal outsiders are able to find adequate skilled jobs - cf. equilibrium V in Table I.

Table 1: Possible Labour Market Outcomes with Insiders and Outsiders

\begin{tabular}{|l|l|l|l|l|}
\hline Equ. & Range of $\mathrm{c}^{\mathrm{m}}$ at TT & $\begin{array}{l}\text { Outsider } \\
\text { threat }\end{array}$ & Employment & Insider Wage setting \\
\hline I & $\mathrm{c}^{\mathrm{m}}>\mathrm{w}^{\mathrm{n}}$ & no & Full employment & $\mathrm{w}^{\mathrm{n}}$ \\
\hline II & $\mathrm{w}^{\mathrm{n}}>\mathrm{c}^{\mathrm{m}}>\mathrm{w}^{\mathrm{sw}}$ & yes & Mis-match unemployment & At TT line \\
\hline III & $\mathrm{w}^{\mathrm{sw}}>\mathrm{c}^{\mathrm{m}}>\mathrm{w}^{\mathrm{g}}$ & yes & Full employment & At TT line \\
\hline IV & $\mathrm{w}^{\mathrm{g}}>\mathrm{c}^{\mathrm{m}}>\mathrm{w}^{\text {all }}$ & Yes & Mis-match unemployment & At TT line \\
\hline V & $\mathrm{w}^{\text {all }}>\mathrm{c}^{\mathrm{m}}>\mathrm{w}^{*}$ & Yes & Full employment & At TT line \\
\hline
\end{tabular}

It should be clear that not all these cases are necessarily possible. We have constructed Figure 3 in such a way that all cases can indeed occur. However, this is because all switch points in the relative wage are defined there. But $w^{g}$ is only defined when the demand shock is sufficiently large relative to the proportion of clever insiders - cf equation (15). Since we assume this to be the case, $w^{s w}$ is defined too, as we have derived above. As a consequence it can be a feasible option for clever outsiders to join the insiders. Whether $w^{\text {all }}$ is defined or not, 
however, and hence whether normal outsiders want to join or not, depends very much on the shares of backward outsiders and clever insiders.

An interesting observation is that the position of $w^{n}, w^{g}, w^{s w}$ and $w^{*}$ relative to each other is independent of the shares of backward and clever outsiders. Hence one might wonder why these different categories of outsiders are distinguished. As can be seen from equation (13), however, the position of the TT-line is highly dependent on these shares. That position determines the range of training costs for which outsiders can pose a credible threat. This range is larger, the higher the share of backward outsiders, as we have indicated above. Therefore it is useful to distinguish between several categories of outsiders.

Finally, notice that the utility of the insiders is always higher than that of the outsiders. First, their training costs are lower than those of the outsiders and therefore the utility of the joining outsiders is lower than that of the insiders. Furthermore the expected utility of the insiders in all equilibria with or without outsider threat is higher than that of the outsiders. In addition the utility of the joining outsiders is higher than that of the over-qualified outsiders in unskilled jobs and that of the unskilled outsiders. Finally, from the analysis above it follows that skill biased technological change improves the relative utility position of skilled employees, because their market power increases. Therefore this model accounts for the rents skilled workers enjoy compared to unskilled workers in recent years induced by skill biased technological change (see, for example Johnson, 1997, or Chennels and Van Reenen, 1999).

\section{Conclusion: the stylized facts reconsidered}

This paper offers an innovative interpretation of the observed differences in the labour markets between the United States and Germany. In the United States, the skilled employees can considerably increase the skill wage demand, because they have higher insider power than in Germany (equilibria I and II). The investment costs for outsiders when they want to be eligible to work in the skilled labour market are so high that they do not pose any or only a small threat to the insiders. The high skill wage mark-up leads to no or only a small additional skilled employee demand. No outsider has a motivation to invest in training and therefore there is no over-qualification and no unemployment (equilibrium I). If outsiders pose a small threat, some mis-match unemployment arises (equilibrium II), because the additional skilled labour demand is not satisfied. 
The insider rents are lower in Germany, because the powerful outsider threat forces the insiders to reduce their wage demand considerably in comparison to their maximum demand (equilibrium IV). The outsider threat is more pervasive, because the training costs for unskilled outsiders are lower. The lower wage mark-up in the wake of skill biased technological change leads to a higher additional skilled labour demand. This additional labour demand is not completely satisfied, because it is only in the interest of a small part of the outsiders to train. These outsiders find a skilled job with certainty, but some skilled jobs are not filled. Therefore we also do not have over-qualification in Germany, but mis-match unemployment.

The interpretation that the differences in wage determination between the USA and Germany stem from higher insider power in the USA is not new, see for example the survey in Teulings and Hartog (1998) and the empirical evidence in Holmlund and Zetterberg (1991). Insider power in this literature is determined by the corporatistic labour market structure in Germany versus the competitive labour market in the USA. This paper asserts that higher insider power in the USA also may be induced by weaker outsider threats due to higher training costs. The crucial empirical question therefore is: are the training costs of the unskilled employees in order to perform skilled tasks lower in Germany than in the US? The direct evidence is scant (OECD, 1999a). One observation is that there are more publicly subsidised training programs for less skilled workers in Germany than in the USA, see OECD (1999a, pp. 163-166). Additional evidence is that in Germany the participation of unemployed in training programmes relative to the participation of employed is higher than in the USA, see also OECD (1999a). Lynch (1994), OECD (1999a), and Acemoglu and Pischke (1999) stress that the incidence of unskilled training in the USA is much lower than in Germany, which may be a consequence of the fact that training is mostly provided by private enterprises. ${ }^{34}$ In addition, it fell between 1983 and 1991 in the USA while training incidence of highly qualified workers increased. In Germany, to the contrary, training levels of both groups of workers increased between 1979 and 1991. Finally, the skill level of unskilled workers in the USA is much lower than in Germany. ${ }^{35}$ Berg (1994) observes for the USA: "The job classification system (...) continues to encourage the division between skilled and

\footnotetext{
${ }^{34}$ Only 4 percent of young workers who are not university graduates get formal training at work in the United States, Lynch (1994).

${ }^{35}$ See the survey in Muysken and Nekkers (2000) or the evidence in Nickell and Bell (1996), Lynch (1994), and Oulton and Stedman (1994). The OECD (1998b) shows that literacy scores of less-educated people are lower in the USA and the UK than in other Western European countries. OECD (1999b) calculates that the change needed in volume of training provided to persons with less than upper secondary education to increase their
} 
nonskilled work. Some plants have (...) broadened the lines of demarcations between jobs." He also notes that this is not the case in comparable German plants, because training of low skill workers entails more general components there. This suggests that the training costs of the unskilled may be exceedingly high, their flexibility low, and that the qualification gap reduces their potential to pose a credible threat to the skilled insiders in the USA.

This interpretation of the evolution of two distinct labour market equilibria in Germany and the USA in the wake of skill biased technological change has some interesting policy implications for labour markets that increasingly need live-long training of especially the skilled labour force. The lower insider power in Germany stems from a credible unskilled outsider threat to replace the skilled insiders and invest in training and education themselves. This higher outsider power may be the consequence of the school system, public training programmes and tax advantages offered for training unskilled employees and unemployed. The high mainly unskilled unemployment, on the other hand, is the consequence of too low incentives for the outsiders to fill the gap in skilled labour demand. It is too costly for most outsiders to sink investment costs in training in comparison to the low wage mark-up for skilled workers.

In order to avoid mis-match unemployment on the labour market and reduce high skilled insider wage mark-ups, the model suggests, to increase the incentives of the unskilled outsiders to invest in human capital in order to be eligible to work in the skilled labour market. This could be achieved by subsidising the sunk part of the training costs of outsiders when they want to join the skilled labour market. In Germany with its many programmes for training of the unemployed, this would mean to focus training subsidies to otherwise sunk costs. Other courses with general knowledge that increase productivity for a long period and in many professions (examples are: reading, writing, or language skills) should not be financed by the state, analogously, because they are in the interest of the unemployed and not burdened by the sunk cost risk. Sunk training costs may for example be costs for knowledge that is outdated quickly (possible examples are knowledge to handle specific computer soft ware or frequently changing tax rules) or that increases productivity in narrowly defined jobs only (possible examples are the specialised professions in the health sector). Possible subsidies or stimuli are for example tax discounts on training expenses, paid training leave, tax levies that oblige employers to spend a certain percentage of their total wage bill in

participation to the level of those with an upper secondary education in percentage is 207 in the United States in contrast to 69 in Germany. 
training or training funds from employees, employers and public sources, see also OECD (1999a) p. 166.

\section{References}

Acemoglu, D., Pischke, J.-S. (1999): Beyond Becker: Training in Imperfect Labour Markets, in: The Economic Journal, 109, pp. 112-143.

Atkinson, A. (2000): The Changing Distribution of Income: Evidence and Explanations, in: German Economic Review, 1, pp. 3-18.

Bartel, A., Sicherman, N. (1998): Technological Change and the Skill Acquisition of Young Workers, in: Journal of Labor Economics, 16, pp. 718-763.

Berg, P. (1994): Strategic Adjustments in Training: A Comparative Analysis of the U.S. and German Automobile Industries, in: Lynch, L. (Ed.): Training and the Private Sector, Chicago: University of Chicago Press, 77-108.

Blanchard, O. and Summers, L. (1986): Hysteresis and the European Unemployment Problem, in: NBER Macroeconomic Annuals, Stanley Fischer (ed.), Cambridge, Mass.: MIT Press, pp. 23-78.

Card, D., Krueger, A. (1995): Myth and Measurement: The New Economics of the Minimum Wage, Princeton: Princeton University Press.

Chennels, L., Van Reenen, J. (1999): Has Technology Hurt Less Skilled Workers? An Econometric Survey of the Effects of Technical Change on the Structure of Pay and Jobs, Institute for Fiscal Studies Discussion Paper, London.

Davis, D. R., (1998): Technology, Unemployment, and Relative Wages in a Global Economy, in: European Economic Review, 42, pp. 1613-1633.

Ebling, G., Hipp, C., Janz, N., Licht, G., and Niggemann, H. (1999): Innovationsaktivitäten im Dienstleistungssektor - Ergebnisse der Innovationserhebung 1997, in: Janz, N., Licht, G. (Hrsg.): Innovationsaktivitäten in der deutschen Wirtschaft, ZEW Wirtschaftsanalysen, 41, Nomos, Baden-Baden.

Fiorillo, F. Santacroce, S., and Staffolani, S. (1999): An Insider-Outsider Model with Nontrivially Heterogeneous Labour Force, in: Gallegati, M. and Kirman, A. (eds.): Beyond the Representative Agent, Edward Elgar: Cheltenham.

Fitzenberger, B. (1999): Wages and Employment Across Skill Groups, An Analysis for West Germany, ZEW Economic Studies 6, Physica, Heidelberg.

Freeman, R., Schettkat, R. (1999): The Role of Wage and Skill Differences in US-German Employment Differences, Jahrbücher für Nationalökonomie und Statistik, 219, pp. 49-66. 
Homlund, B., Zetterberg, J. (1991): Insider Effects in Wage Determination - Evidence from five countries, in: European Economic Review, 35, pp. 1009-1034.

Johnson, G. (1997): Changes in Earnings Inequality: The Role of Demand Shifts, in: Journal of Economic Perspectives, 11, pp. 41-54.

Juhn, C., Murphy, K. and Pierce, B. (1993): Wage Inequality and the Rise in Returns to Skill, in: Journal of Political Economy, 101, pp. 410-442.

Krugman, P. (1995): Growing World Trade: Causes and Consequences, in: Brookings Papers on Economic Activity, 1, pp. 327-362.

Layard, R. Nickell, S. and Jackman, R. (1991): Unemployment - Macroeconomic Performance and the Labour Market, Oxford University Press, Oxford.

Lindbeck, A., Snower, D. (1988): Cooperation, Harassment, and Involuntary Unemployment: An Insider-Outsider Approach, in: American Economic Review, 78, pp. 167-188.

Lindbeck, A., Snower, D. (1990): Cooperation, Harassment, and Involuntary Unemployment: Reply, in: American Economic Review, 80, pp. 631-636.

Lindbeck, A., Snower, D. (1994): Patterns of Unemployment: An Insider-Outsider Analysis, CEPR Discussion Paper 960, London.

Lynch, L. (1994): Introduction, in: Lynch, L. (Ed.): Training and the Private Sector , Chicago: University of Chicago Press, 1-24.

Manacorda, M., Petrongolo, B. (1999), Skill Mismatch and Unemployemnt in OECD Countries, in: Economica, 66, pp. 181-207.

Muysken, J., Nekkers, G. (2000), Skilled-Unskilled Wage Differentials, Unemployment and Hours of Work: The Case of America and Europe, Merit Research Memorandum 2000-002, Maastricht.

Muysken, J. Zwick, T. (1999), Human Capital Creates Insider Power, Discussion paper, No. 99-25, Centre for European Economic Research(ZEW), Mannheim

Nickell, S. (1997): Unemployment and Labor Market Rigidities: Europe versus North America, in: Journal of Economic Perspectives, 11, pp. 55-74.

Nickell, S., Bell, B. (1996), Changes in the Distribution of Wages and Unemployment in OECD Countries, in: American Economic Review, 86, pp. 302-308.

OECD (1996a) Employment Outlook, Paris.

OECD (1996b) Science, Technology and Industry Outlook, Paris.

OECD (1998a) Education at a Glance, Paris.

OECD (1998b), Human Capital Investment: An International Comparison, Paris. 
OECD (1999a) Employment Outlook, Paris.

OECD (1999b), Education Policy Analysis, Paris.

Oulton, N. and Steedman H. (1994): The British System of Youth Training, in: Lynch, L. (Ed.): Training and the Private Sector, Chicago: University of Chicago Press, 61-76.

Pannenberg, M. (1995): Weiterbildungsaktivitäten und Erwerbsbiographie: eine empirische Analyse für Deutschland, Campus Verlag, Frankfurt am Main.

Siebert, H. (1997): Labor Market Rigidities: At the Root of Unemployment in Europe, in: Journal of Economic Perspectives, 11, pp. 37-54.

Steiner, V., Mohr, R. (1998): Industrial Change, Stability of Relative Earnings, and Substitution of Unskilled Labor in West Germany (Discussion paper), No. 98-22, Centre for European Economic Research (ZEW), Mannheim.

Teulings, C., Hartog, J. (1998): Corporatism or Competition? Labour Contracts, Institutions and Wage Structures in International Comparison, Cambridge University Press, Cambridge.

Topel, R. (1997): Factor Proportions and Relative Wages: The Supply-Side Determinants of Wage Inequality, in: Journal of Economic Perspectives, 11: 55-74.

Zon, van A., Muysken, J, and Meijers, H. (1998): Asymmetric Skill Substitution, Labour Market Flexbility, and the Allocation of Qualifications, in: Heijke, H., Borghans, L.: Towards a Transparent Labour Market of Educational Decision, Ashgate, Aldershot. 


\section{Annex: A simple formal representation}

This annex presents a standard two-goods, two-factor general equilibrium model (compare also Davis, 1998).

We distinguish between skilled labour $H$ and unskilled labour $L$ as factors of production, with prices $w_{H}$ and $w_{L}$, respectively. The relative price is $w=w_{H} / w_{L}$. Total supply of skilled and unskilled labour is $n$ and $(1+b) m$, respectively, and relative supply is given by $h^{*}=n /(m(1+b))$. Moreover, two goods are produced under constant returns to scale: a skillintensive good $X$ and a skill-extensive good $Y$, where $P$ is the relative price of $X$ to $Y$, i.e. $P=$ $P_{X} / P_{Y}$.

Let consumers have the following utility function:

$U=\left[X^{\rho}+Y^{\rho}\right]^{1 / \rho} \quad 0<\rho<1$,

Maximization of (A1) subject to the budget constraint $I=P_{X} X+P_{Y} Y$, with a given income $I$ yields:

$$
\frac{X}{Y}=\left[\frac{P_{X}}{P_{Y}}\right]^{-\frac{1}{1-\rho}} .
$$

The production of goods is represented by a Cobb-Douglas production function:

$$
\begin{aligned}
& X=A{H_{X}}^{\alpha} L_{X}{ }^{1-\alpha} \\
& Y=H_{Y}{ }^{\beta} L_{Y}{ }^{1-\beta}
\end{aligned}
$$

where $\beta<\alpha$ indicates that $X$ is the skill-intensive good and $Y$ the labour-intensive one. The parameter $\mathrm{A}$ is a productivity index.

Maximization of the profit function

$$
\Pi=P_{X} \cdot X+P_{Y} \cdot Y-w_{H}\left(H_{X}+H_{Y}\right)-w_{L}\left(L_{X}+L_{Y}\right),
$$

subject to equations (A3) yields:

$$
\begin{aligned}
& w_{H}=\alpha A P_{X}\left[\frac{H_{X}}{L_{X}}\right]^{\alpha-1}=\beta P_{Y}\left[\frac{H_{Y}}{L_{Y}}\right]^{\beta-1}, \\
& w_{L}=(1-\alpha) A P_{X}\left[\frac{H_{X}}{L_{X}}\right]^{\alpha}=(1-\beta) P_{Y}\left[\frac{H_{Y}}{L_{Y}}\right]^{\beta} .
\end{aligned}
$$

Eliminating $H_{X} / L_{X}$ and $H_{Y} / L_{Y}$ respectively yields: ${ }^{36}$

${ }^{36}$ Here $k_{1}^{\alpha-\beta}=\alpha^{\alpha}(1-\alpha)^{1-\alpha} / \beta^{\beta}(1-\beta)^{1-\beta}$. 


$$
\frac{w_{H}}{w_{L}}=k_{1}\left[\frac{P_{x}}{P_{y}}\right]^{\frac{1}{\alpha-\beta}} A^{\frac{1}{\alpha-\beta}} \text {. }
$$

When we look at demand for labour more explicitly, we define for aggregate demand:

$H=H_{X}+H_{Y}$

$L=L_{X}+L_{Y}$

Let us define for simplicity: $h=H / L, h_{X}=H_{X} / L_{X}$ and $h_{Y}=H_{Y} / L_{Y}$. Then we can derive from equations (A6) and (A7):

$$
\frac{L_{X}}{L_{Y}}=\frac{h_{Y}-h}{h-h_{X}} .
$$

Actually, equation (A4) yields $h_{X}$ and $h_{Y}$ as a function of relative prices: ${ }^{37}$

$$
h_{X}=k_{X}\left[\frac{A P_{X}}{P_{Y}}\right]^{-\frac{1}{\alpha-\beta}} \text { and } \sim h_{Y}=k_{Y}\left[\frac{A P_{X}}{P_{Y}}\right]^{\frac{1}{\alpha-\beta}} \text {. }
$$

Moreover, combining equations (A2) and (A3) also yields $L_{X} / L_{Y}$ as a function of relative prices:

$$
\frac{L_{x}}{L_{Y}}=\frac{h_{Y}{ }^{\beta}}{h_{X}{ }^{\alpha}}\left[\frac{P_{X}}{P_{Y}}\right]^{-\frac{1}{1-\rho}} \frac{1}{A} .
$$

Substitution of equations (A9) and (A10) in (A8) then results in a relation between $h$ and $P$ which represents the demand curve for labour:

$$
h^{d}=A^{\frac{1}{\alpha-\beta}} P^{-\frac{1}{\alpha-\beta}} \frac{k_{X} k_{Y}^{\beta} P^{-\frac{\rho}{1-\rho}}+A k_{Y} k_{X}^{\alpha}}{k_{Y}{ }^{\beta} P^{-\frac{\rho}{1-\rho}}+A k_{X}^{\alpha}} .
$$

${ }^{37}$ Here $k_{X}{ }^{\alpha-\beta}=\beta^{\beta}(1-\beta)^{1-\beta} / \alpha^{\beta}(1-\alpha)^{1-\beta}$ and $\sim k_{Y}{ }^{\alpha-\beta}=\beta^{\alpha}(1-\beta)^{1-\alpha} / \alpha^{\alpha}(1-\alpha)^{1-\alpha}$. 